\title{
eLyra
}

\section{Pauliceia parnasiana: Mário de Andrade leitor e poeta nas margens de Baptista Cepellos}

\author{
Ligia Kimori \\ bolsista da FAPESP \\ Faculdade de Filosofia, Letras e Ciências Humanas - FFLCH/USP
}

Resumo: O diálogo de Mário de Andrade com os parnasianos, brasileiros e franceses, a ser acompanhado ou decodificado em sua biblioteca, nas suas matrizes e na sua marginália, oferece novo alento ao estudo de sua poesia. As marcas da cidade moderna em Pauliceia Desvairada, o convite à contemplação, no "Rito do irmão pequeno”, e o rio, n'“A meditação sobre o Tietê”, ganham novas e significativas dimensões quando se observa a latência desses temas, de determinadas construções e mesmo de escolha vocabular em sua leitura d'Os Bandeirantes, de Baptista Cepellos, obra na qual o parnasiano vale também como um pré-modernista.

Palavras-chave: Poesia de Mário de Andrade, Baptista Cepellos, Parnasianismo e pré-modernismo, Biblioteca de escritores

Abstract: The dialogue of Mário de Andrade with the Parnassians, Brazilian and French, to be accompanied or decoded in his library, in his matrices and in his margins, offers a fresh encouragement to the study of his poetry. The marks of the modern city in "Pauliceia Desvairada", the invitation to contemplation, in the "Rito do Irmão Pequeno" and the river, in "A Meditacão Sobre oTietê" gain new and significant dimensions when we look at the latency of these themes, of certain constructions and even the vocabulary choices in his reading in "Os Bandeirantes", by Baptista Cepellos, a work in which the Parnassian also counts as a pre-modernist.

Keywords: Poetry of Mário de Andrade, Baptista Cepellos, Parnasianism and premodernism, Library of writers 
A marginália conservada nos volumes parnasianos, nas estantes de Mário de Andrade, ${ }^{1}$ manifesta a pesquisa apurada nos versos, nas formas, sons e temas, desde a juventude do leitor-poeta que conhece muito bem versificação; que acumula lições. Que é capaz de distinguir quebra de harmonia nas estrofes. Nas margens dos livros parnasianos, ele exercita seu aprendizado quando sugere modificações que representam, de fato, apropriação: ensaia rimas, propõe versos, esboça poemas. Impregnado das lições de poetas consagrados, brasileiros e franceses, trabalha no espaço do autor, experimenta palavras, sonoridade; cria sua versão, põe em prática possibilidades de fazer poesia.

Em suas notas, Mário de Andrade aprecia poemas, observa-Ihes a estrutura, o tipo de construção, pois, fundamentado em muito estudo, distingue bem o estilo parnasiano. Avalia sempre a métrica, a relação conteúdo-forma e os muitos vocábulos recolhidos pelo seu lápis. Mário modernista alimenta-se de estruturas parnasianas que suas anotações tanto valorizam como contestam. Somado a outras experiências estéticas, esse amálgama de leituras desenha contornos do escritor; integra-se à sua própria criação. Essa marginália desvenda elementos poéticos que Ihe parecem essenciais, construções que receberam a atenção do leitor, deixando vestígios de seus estudos, parte fundamental em sua formação intelectual.

O diálogo com os poetas parnasianos, autenticado pela farta marginália, testemunha o interesse particular do leitor. As notas esparsas, as discussões alongadas em espaços em branco nas páginas de livros, comentários, comparações e tentativas de reelaborar versos dos outros fazem da sua biblioteca um espaço de leitura-escritura que acusa também matrizes de projetos artísticos e críticos, de técnicas de composição e feitura de versos. Cabe abrir parênteses para cogitar, à luz da crítica genética, que os diálogos intertextuais travados na biblioteca dos escritores guardam matrizes que tanto se explicitam na marginália como se conservam em estado latente, até o instante em que textos desses especiais leitores são desvendados.

Dentre o conjunto das obras parnasianas pertencentes a Mário de Andrade, somando 35 títulos brasileiros e 9 franceses, ${ }^{2}$ seleciono o exemplar anotado da primeira edição d'Os Bandeirantes, de Baptista Cepellos (São Paulo, Estabelecimento typographico do FANFULLA, 1906). Poesia de característica parnasiana, mas, ao mesmo tempo, valendo como pré- 
modernista, ao explorar o tema da cidade do século XX, este livro se mostra como possível matriz de temas, versos e estruturas no poeta paulistano. Em meio a outros paradigmas literários, os parnasianos ressoam na glosa moderna de sonetos do poeta-leitor Mário de Andrade, nas aliterações e assonâncias tomadas com outras perspectivas, em certas apropriações de adjetivos, estruturas métricas, construções, até "ousadias"; diálogo que revela parcelas do expressivo legado parnasiano.

O poeta paulista Baptista Cepellos (1872-1915), importante tradutor de Mallarmé, que a história literária alinha entre os simbolistas, navega no parnasianismo em Os Bandeirantes, publicado em 1906. Ultrapassa, contudo, a escola de Banville ao tocar no prémodernismo, o que hoje se pode compreender. Prefaciado por Olavo Bilac, que reconhecia a relevância daqueles versos para o tempo então vivido, "prosaico e sem sabor" (1906: 9), o livro focaliza a fundação de São Paulo pelas bandeiras; nomeia heróis, exaltando traços da História paulistana, a constituição de um povo e de uma cidade brasileira. Para Bilac, desde Gonçalves Dias não se conseguia esse alcance nacionalista.

Percorrendo as páginas d'Os Bandeirantes, o poeta-leitor Mário de Andrade sublinha alguns vocábulos, tomando nota de sinônimos e de significados, como no verso 15 de "Palmares" - "Ora, entre abysmos, sobe o muro impervio e bronco" (Cepellos 1906: 73) -, no qual sublinha "impérvio" e registra: "intransitável / Onde não ha caminho". ${ }^{3}$ Inventaria também expressões e temas ao apor traços duplos ou simples à margem das estrofes; seleciona títulos de poemas que lhe parecem interessar pela forma ou conteúdo, pela matéria poética significativa. A sonoridade não escapa ao lápis que assinala aliterações e assonâncias peculiares. Essa marginália demarca o interesse em procedimentos de construção, na recolha de imagens da cidade; testemunha a leitura cerrada dos versos.

O diálogo do leitor moço acolhe a obra de Baptista Cepellos na medida em que retoma temas, chancela soluções estilísticas e mimetiza certas formas. N'Os Bandeirantes, a contemplação da natureza frequenta muitos poemas, onde se observam, com minúcia, os sons delicados e os movimentos lentos do ambiente, saboreando a solidão. "Mata virgem" apresenta momentos assim:

Entremos. Tudo dorme, entre as colunas graves (Cepellos 1906: 159)

$[\ldots]$ 
Enfiemo-nos por ele, através desses troncos (ibidem)

[...]

Ouves? Começa mal! Um barulho distinto... (idem: 160)

O estilo dialógico, neste poema de Cepellos, assemelha-se ao "Rito do irmão pequeno", poema de Mário de Andrade, datado de 1931, segundo Telê Ancona Lopez. A descrição nos versos, em especial, conduz a aproximação entre os dois textos poéticos, assim como o imperativo, no convite do eu-lírico. Escreve o poeta moderno que busca, por sua vez, o espaço da Amazônia:

Venha comigo. Por detrás das árvores, sobrado dos igapós, (Andrade 2013: 455)

Matemos a hora que assim mataremos as sombras sinistras, (ibidem)

Percebo que o gesto compassado de observar a natureza aparece nos dois poemas, inclusive na escolha vocabular:

Contemplemos, em torno, a paisagem robusta (Cepellos 1906: 161)

Será preciso contemplá-las, e a paciência,

Irmão pequeno, é que entreabre as melhores visões. (Andrade 2013: 456)

Nas páginas de seu exemplar, o leitor sublinha a aliteração sibilante do verso 185 , "Sôa surda e subtil, num sussurro em surdina,", e destaca com dois traços à margem uma sequência longa de imagens que evocam a atmosfera em meio à natureza:

\footnotetext{
Vem nas aragens finas

Um perfume sensual de hervas e de resinas

Que o sol amachucou durante o dia inteiro.

Ai! sente-se um languor, respirando esse cheiro,

Como si a nossa fronte, a pender de cansaço,

Rolasse com prazer na quentura de um braço!

Dahi a pouco, apparece a lua branca e plena,

Que fica a rebrilhar, sonhadora e serena,

Acima de um granito onde irradia tanto,

Que lembra um resplendor á cabeça de um santo... (Cepellos 1906: 165)
} 
O recorte reforça a ideia de entorpecimento e preguiça amparados pelos odores do ambiente, versos que revelam detalhes de uma natureza descrita pelo viés sensível, com impressões precisas a esmiuçar o espaço; mesma atmosfera retomada em "Rito do irmão pequeno", na criação do poeta-leitor:

\footnotetext{
É pleno dia. O ar cheira a passarinho.

O lábio se dissolve em açúcares breves,

O zumbido da mosca embalança de sol. (Andrade 2013: 458)
}

À matriz parnasiana, junta-se a matriz romântica que emerge na feitura desse poema da maturidade, como analisa Telê Ancona Lopez em "Mário de Andrade leitor e escritor: matrizes e marginália". ${ }^{4}$ Para a estudiosa, o Reno do poema "Die Lotoblume ängstige", de Heirich Heine, deságua no Amazonas, rio que a criação do poeta brasileiro absorve na viagem do Turista Aprendiz ao Norte do Brasil, em 1927. Delineia a apropriação do sentido maior, sem anotação marginal, mas latente, os versos de Baptista Cepellos, acima citados, ou os Alberto de Oliveira em "Volubilis", de Poesias (Segunda série: Livro de Emma, Alma livre, Terra natal, Alma em flor, Flores da serra, Versos de saudade. Rio de Janeiro, Livraria Garnier, 1912, 30-32). Surge, então, no "Rito", o sentido da plenitude na contemplação para a qual o eu-lírico convida o irmão pequeno que capta a Schwesterlein (irmã pequena) do poema "Die Lotoblume ängstige" de Heine, tendo já conhecido, em "Volubilis", a valorização de um recanto de solidão e recolhimento. Na margem superior da página de Alberto de Oliveira, o leitor Mário aplaude os versos: "Esta poesia é linda. Notar as estrofes 2, 3, 4 e 5ㅁ, que são verdadeiras miniaturas adoráveis":

\section{Oh! Que poesia estranha}

Derrama a luz do luar nas abas da montanha!

Lá muita vez minh'alma

Vae buscar de um coqueiro a movediça palma;

Ahi pousa e ouve enlevada as estrophes soturnas

Com que o vento a gemer quebra a nocturna calma,

Enlapado nas furnas.

Outra vez (e imaginas 
Que captivo me tens!) acompanha as neblinas;

Aos pincaros se atreve,

Sobe e, aerea, a girar, phantastica, descreve

Ronda lasciva ao luar; roda um momento, vôa,

E vem bordar de orvalho um véu de rendas, leve,

Aos juncos da lagoa.

Alli, quieto, sombrio,

Ha um bosque e dentro delle a agua de um grande rio;

Sobre Ella o matto denso

Tece um caramanchel, do cipoal suspenso;

No barreiro amarello, abrindo em cada fragua,

Brotam flores e alastra um espiral de incenso

Á superfície d'agua.

Ao pôr do sol, a essa hora

Em que um toque de luz o occaso aviva e côra,

E infinita tristeza

Véla como de crepe a toda a natureza,

Alli scisma minh'alma: as arvores a viram!

Olha o rio e acompanha á flor da correnteza

As folhas que cahíram. (Oliveira 1912: 30)

A atmosfera que viceja neste poema de Alberto de Oliveira - contemplativa, minuciosa, carregada de impressões sensíveis -, aparece também em outros poemas d'Os Bandeirantes, sem anotações do leitor. Em "A sesta", as semelhanças, vale especular, estendem-se ao "Rito do irmão pequeno", afirmando, em Batista Cepellos, a sua matriz:

Na floresta e no vale, e em toda a Natureza

Predomina uma funda e gostosa molleza...

Agora, deve ser uma delícia a gente

Descer ao ribeirão e, regaladamente,

Beber um pouco d'agua, em folha de tayoba;

Depois, como um lagarto, ir comer guabiroba;

E, desfrutando a sesta, à maneira de um bicho,

Deixar que o pensamento adeje a seu capricho... (Cepellos 1906: 114) 
Testemunha a mesma matéria poética o soneto "Tropical", quando nos tercetos a preguiça é exercida com vagar, pode-se dizer:

\author{
Unem-se a terra e o céu, no horizonte em fumaça... \\ E, bambo de calor, busco a amável frescura \\ Da sombra, onde a preguiça ao meu corpo se enlaça. \\ O sono, pouco a pouco, aproxima, aproxima... \\ Reina em tudo uma paz tão beatifica e pura \\ Que é doce estar assim, de papo para cima! (idem: 121)
}

Para além da coincidência temática e na construção das imagens, é interessante constatar o tom prosaico em nada condizente com o rigor formal parnasiano, como se lê no último verso: "Que é doce estar assim, de papo para cima!". A dessacralização na escolha vocabular nos poemas de Baptista Cepellos põe-se em consonância com formas dessacralizadas ao gosto dos modernistas, mais tarde. É possível imaginar que essa solução poética renovadora tenha agradado o leitor Mário como possibilidade de enriquecimento e constituição de um modo de escrever.

O livro de Baptista Cepellos, além de celebrar a natureza brasileira na demorada contemplação, dedica-se a restituir os feitos dos Bandeirantes. As muitas imagens da cidade em construção, do progresso que provoca o apagamento das paisagens e a descrição da São Paulo em movimento, na mudança das épocas, moldam boa parte dos versos mais que parnasianos, de características pré-modernistas. Difícil não lembrar o eco, em Pauliceia Desvairada, destes trechos de "S. Paulo antigo", poema longo de Cepellos, escrito em quadras em que se retoma a interjeição de Castro Alves:

Evoquemos, portanto, a Pauliceia

Daqueles dons senhores arrogantes,

Cujos nomes preclaros dão ideia

De um sangue azul em pulso de gigantes!

São Paulo dos violões de rua em rua, Soluçando uma toada merencória... 
E Castro Alves gritando, à luz da lua:

'Oh, Liberdade! oh, Ponte Grande! oh, Gloria!'

$[\ldots]$

São Paulo da garoa peneirante:

Um pálido lampião ao longe brilha;

Range uma portilhola e, ao mesmo instante,

Escorrega uma sombra de mantilha... (idem: 42)

Na sua leitura, o jovem Mário destaca a última estrofe, onde o poeta parnasiano ressalta a cidade que se expande, repetindo o uso da interjeição ao tomá-la para si:

Hoje, S. Paulo meu, não há terreno

Que te baste, no ardor com que te expandes

Mas ai! quando tu foste assim pequeno

Como os teus grandes homens eram grandes (idem: 43)

No confronto dos versos de Batista Cepellos com os de Mário modernista de "Os cortejos", "Paisagem no 1" e "Paisagem no 2", em Pauliceia Desvairada, no ano de 1922, percebem-se ângulos similares na visão da cidade, quando, recorrendo a metáforas, este dirige o olhar aos habitantes: "Pauliceia - a grande boca de mil dentes; [...] Giram homens fracos, baixos, magros..." ("Os cortejos", Andrade 2013: 79); à cidade molhada: "Minha Londres das neblinas finas!" ("Paisagem no 1", idem: 86); e quando constroi imagens como esta: "São Paulo é um palco de bailados russos" ("Paisagem no 2", idem: 101). Aproximam-se os modos de tratar o espaço urbano, no contato afetuoso com a cidade que é diversa a cada vez, nas interjeições reiteradas ("oh!", "ai"). N'Os Bandeirantes, o lápis do leitor sublinha justamente a representação da cidade do século XX em ebulição, como aparece no soneto "O fundador de S. Paulo":

Rumoreja a cidade, em febril movimento.

Ondeia como um rio a immensa populaça;

E, maculando o olhar azul do firmamento,

Erguem-se as chaminés golphejando fumaça. 
Estende-se o commercio em soberbo incremento;

Circula como um sangue a riqueza na praça;

E, numa rapidez superior á do vento,

Os prelos dão á luz e o trem de ferro passa... (Cepellos 1906: 53)

As imagens da cidade moderna, valorizada no movimento oferecido pelos versos de Cepellos, evidenciam o interesse do leitor acerca do tema. Muitas dessas imagens, vindas também, possivelmente, do poeta Verhaeren, de quem também Mário de Andrade foi fervoroso leitor, encontram simetria em Pauliceia Desvairada, nos versos de "Paisagem no 2": "as oficinas tossem" (Andrade 2013: 101); ou de "Paisagem no 4": "caminhões rodando, as carroças rodando / rápidas as ruas se desenrolando, / rumor surdo e rouco, estrépitos, estalidos... / E o largo coro de ouro das sacas de café!..." (idem: 109).

Em "Palmares", o jovem leitor colhe, uma vez mais, ideias que se ligam ao imaginário da cidade em expansão, sinalizando um termo com exclamações duplas; um termo que hoje se pode abrigar no pré-modernismo:

Grande é a sua missão: rasgar com energia,

Através dos sertões, um victorioso ingresso,

Pelo qual o Brasil ha de fazer um dia

Correr triumphalmente o carro do progresso !! (Cepellos 1906: 91)

Baptista Cepellos canta a cidade esculpida pelo impulso dos bandeirantes, pelas moções que o rio paulista testemunhou em seu curso por todo o estado, de leste a oeste; o velho Tietê, como o apelida carinhosamente o parnasiano-pré-modernista nas confidências que lhe faz em quinze quadras rimadas, no poema que carrega o nome do rio. Debruçado às margens, ao cair da tarde, em prolongada meditação, o eu-lírico entrega, ao murmúrio das águas, o pavor do progresso que o avassala:

De tarde, quando o sol poucos brilhos expande,

Sozinho, a meditar em tanto não sei quê,

Tomo o rumo da Luz, vou até a Ponte Grande,

Afim de conversar com o meu velho Tietê... 
A cabeça recosto, e, por cima da grade,

Vejo as águas em todo o seu largo trajeto;

Então, ele me conta a história da Cidade,

Como um velho guerreiro a distrair o neto...

Cofiando lentamente a barba de cem anos,

O bom velho me conta essa história, e também

Fala do tempo de hoje e dos seus desenganos,

Mas não fica zangado e não xinga ninguém.

Refere-se às monções que ele, soberbamente,

Tantas vezes levou, na faina das conquistas,

Escutando pulsar o coração valente

Daquela geração de valentes paulistas!

Tempo em que, num tropel, num bizarro alvoroço

De armas e embarcações, como agora não ha,

Partiu para o sertão, rumo de Matto-Grosso,

Paschoal Moreira, fundador de Cuyabá (idem: 35-36)

A temática dos rios figura em muitos poemas de Mário de Andrade ${ }^{5}$ e o Tietê firmase como linha de força nessa poesia desde o modernismo da década de 1920, até os versos de "A meditação sobre o Tietê", concluídos dias antes da morte do escritor, em fevereiro de 1945. "O Tietê" de Batista Cepellos desenha-se como matriz de "Tietê", em Pauliceia Desvairada, poema de 13 versos que, em 1922, toca na ambição das monções e indica caminho por Mato Grosso, como Baptista Cepellos:

Era uma vez um rio...

Porém os Borba-Gatos dos ultranacionais esperiamente!

Havia nas manhãs cheias de sol do entusiasmo

as moções da ambição...

E as gigânteas vitórias!

As embarcações singravam rumo do abismal descaminho 
Arroubos... Lutas... Setas... Cantigas... Povoar!

Ritmos de Brecheret!... E a santificação da morte!

Foram-se os ouros!... E o hoje das turmalinas!...

- Nadador! vamos partir pela via dum Mato-Grosso?

- Io! Mai!... (Mais dez braçadas.

Quina Migone. Hat Stores. Meia de seda.)

Vado a pranzare con la Ruth. (Andrade 2013: 85)

A imagem da modernidade, entretanto, amplia-se no sarcasmo desse poema de Mário de Andrade, somado ao final prosaico na língua dos imigrantes plasmados à São Paulo dos anos 1920, em meio às mudanças que subvertiam o espaço urbano e impressionavam, conforme conta o historiador Nicolau Sevcenko:

De tal modo o estranhamento se impunha e era difuso, que envolvia a própria identidade da cidade. Afinal, São Paulo não era uma cidade nem de negros, nem de brancos e nem de mestiços; nem de estrangeiros e nem de brasileiros; nem americana, nem europeia, nem nativa; nem era industrial, apesar do volume crescente das fábricas, nem entreposto agrícola, apesar da importância crucial do café; não era tropical, nem subtropical; não era ainda moderna, mas não tinha mais passado. (Sevcenko 1992: 31)

A cidade, já diferente daquela cantada por Baptista Cepellos no início do século, ganharia ainda outros contornos estéticos e sociais, elementos evocados nos versos de "A meditação sobre o Tietê", de Lira Paulistana, onde o poeta moderno Mário de Andrade retoma o tema do rio e sua cidade, avaliando a própria trajetória, sozinho, à noite, debruçado sobre as águas:

É noite. E tudo é noite. Debaixo do arco admirável

Da Ponte das Bandeiras o rio

Murmura num banzeiro de água pesada e oliosa.

É noite e tudo é noite. Uma ronda de sombras,

Soturnas sombras, enchem de noite de tão vasta

O peito do rio, que é como si a noite fosse água,

Água noturna, noite líquida, afogando de apreensões

As altas torres do meu coração exausto. De repente 
O ólio das águas recolhe em cheio luzes trêmulas,

É um susto. E num momento o rio

Esplende em luzes inumeráveis, lares, palácios e ruas,

Ruas, ruas, por onde os dinossauros caxingam

Agora, arranha-céus valentes donde saltam

Os bichos blau e os punidores gatos verdes,

Em cânticos, em prazeres, em trabalhos e fábricas,

Luzes e glória. É a cidade... É a emaranhada forma

Humana corrupta da vida que muge e se aplaude.

E se aclama e se falsifica e se esconde. E deslumbra. (Andrade 2013: 531)

A meditação implica também interpelar o rio. Em longos monólogos, dois poetas - o modernista bem como o parnasiano e pré-modernista - conversam com a história marcada naquele ponto da cidade. Passado semelhante versado em momentos distintos, a coincidência do local escolhido para se aproximar do Tietê abriga também sinais de cada período:

De sua posição estratégica, a Ponte Grande acompanhou o crescimento da cidade em sua direção e, já em ferro fundido sobre pilares de pedra, tornou-se um dos pontos mais aprazíveis para a população, local preferido desde fins do século XIX para fotografias pitorescas. (...) Com a retificação do leito do Tietê, a Ponte Grande foi demolida. Em seu lugar foi erguida outra, em arco de concreto, marco da modernidade paulista. A Ponte das Bandeiras foi inaugurada em 1942. (Ohtake apud Major Neto 2006: 121)

A ideia de murmúrio das águas, descrita pelo poeta parnasiano: - "Tem saudades também o desditoso Rio! / E então a sua voz é cortar rochedo, / Quando, quase a chorar, num longo murmúrio, / Começa a recitar Alvares de Azevedo! (Cepellos 1906: 37) expandese na meditação de Mário de Andrade que adota os verbos "mugir", "aclamar", "deslumbrar", "desgastar", "dispersar", "contemplar", no contato com o rio que contempla e ao qual vai, aos poucos, se integrando. Do mesmo modo, o motivo do progresso na cidade renovada repete-se e tem por testemunha o mesmo curso de águas. Assim como Baptista Cepellos pergunta ao velho amigo - "Que importa a ingratidão da Cidade querida, / Que de longe, lhe mostra os altivos torreões?" -, o poeta modernista interroga as águas: 
Meu rio, meu Tietê, onde me levas?

Sarcástico rio que contradizes o curso das águas

E te afastas do mar e te adentras na terra dos homens,

Onde me queres levar?...

Por que me proíbes assim praias e mar, por que

Me impedes a fama das tempestades do Atlântico

E os lindos versos que falam em partir e nunca mais voltar? (Andrade 2013: 532)

Na conclusão do poema, o parnasiano revela ainda facetas do próprio rio na tentativa de acompanhar a história que ali se dilui - "Ah corrente fatal! ah teimosa corrente, / Que o fez grande demais para ser infeliz!" (Cepellos 1906: 38) - enquanto em "A meditação sobre o Tietê", o poeta moderno encerra no mesmo tom melancólico e amargo em que foi mergulhando a cada verso, misturando-se às águas que the servem de espelho:

\author{
[...] e tudo é noite. Sob o arco admirável \\ Da ponte das bandeiras, morta, dissoluta, fraca, \\ Uma lágrima apenas, uma lágrima, \\ Eu sigo alga escusa nas águas do meu Tietê. (Andrade 2013: 543)
}

A análise das anotações de leitura de Mário de Andrade nos volumes parnasianos pertencentes a sua biblioteca deixa transparecer a recusa de determinadas escolhas poéticas, mas permite observar continuidades formais e estéticas - cuidado com a sonoridade, aproveitamento de certas estruturas do verso, impregnação de cadência métrica. Mais do que isso, há também algo de instigante no parnasianismo que desperta os olhos do leitor ávido em estudar poesia, recolher achados e constâncias pertinentes. Em Baptista Cepellos, como aqui se examinou, a abordagem da cidade e a atmosfera de contemplação desenham-se como matrizes possíveis de versos do poeta Mário de Andrade que, apropriando-se de temas e estruturas, resgata elementos d'Os Bandeirantes.

Perceber que versos parnasianos significam matéria poética e procedimentos de construção interessantes, avaliando o que reside de sólido e valioso nessa estética, proporciona uma visão mais acertada da literatura brasileira. O vocabulário prosaico de Baptista Cepellos, adotado em alguns versos, certamente oferece ao jovem leitor de poesia, dedicado a estudar e comparar obras, a possibilidade de subverter a adequação vocabular, 
buscar diferentes formas de expressão. Ler essas obras acompanhando as indicações de estudo de Mário de Andrade ajuda a ampliar o entendimento de sua própria poesia e admite reavaliar os diálogos estabelecidos entre parnasianos e modernistas.

Não acusar os parnasianos junto dos manifestos modernistas, medindo o passado estético com parâmetros críticos presentes, evita cobrar de uma escola a antecipação de estruturas e temas de outro tempo, produto de um momento bastante diferente. Permite ainda enxergar o alcance da própria estética parnasiana dentre as demais produções literárias nacionais e avaliar suas verdadeiras características formais, as soluções estilísticas adotadas pelos poetas, recursos importantes de métrica e construção de versos, além de precisar o alcance das produções no período e nas publicações que prosseguem, apurando sua singularidade e relevância.

\section{NOTAS}

\footnotetext{
${ }^{1} \mathrm{O}$ trabalho de classificação e transcrição dessa marginália liga-se aos volumes conservados na Coleção Mário de Andrade, no acervo da Biblioteca do Instituto de Estudos Brasileiros da Universidade de São Paulo (IEB-USP), bem como aos títulos parnasianos do Brasil e da França na coleção doada pelo escritor à Biblioteca Pública de Araraquara, em 1943.

${ }^{2}$ Esta pesquisa filia-se ao projeto coletivo coordenado por Telê Ancona Lopez, Bibliotecas de Escritores e a Criação Literária, vinculado à área de Literatura Brasileira da FFLCH-USP e do IEB-USP, projeto que também se liga ao Núcleo de Estudos Bibliotecas de Escritores: Da leitura à criação, no LABIIEB-USP.

${ }^{3} \mathrm{O}$ itálico foi adotado na metodologia de transcrição das notas de Mário de Andrade, quando se trata de manuscrito do leitor. Por isso, assim aparecerá nas citações.

${ }^{4}$ V. Guavira Letras, no 23, Universidade Federal de Três Lagoas/MS, 32-33.

${ }^{5}$ Aprofunda essa temática o importante trabalho de José Emílio Major Neto, A Lira Paulistana de Mário de Andrade: A Insuficiência fatal do Outro, tese de doutoramento orientada pela Profa lumna Simon, USP/SP.
} 


\section{Bibliografia}

Andrade, Mário de (2013), Poesias Completas, ed. Telê Ancona Lopez e Tatiana Longo Figueiredo, São Paulo, Nova Fronteira.

Cepellos, Baptista (1906), Os Bandeirantes, São Paulo, Estabelecimento typographico do FANFULLA.

Lopez, Telê Ancona (2016), "Mário de Andrade leitor e escritor: matrizes e marginália", Guavira Letras, no 23, Universidade Federal de Três Lagoas/MS, 14-33.

Major Neto, José Emílio (2006), A Lira Paulistana de Mário de Andrade. A insuficiência fatal do Outro, FFLCH - Universidade de São Paulo, tese de doutoramento.

Oliveira, Alberto de (1912), Poesias. Segunda série: Livro de Emma, Alma livre, Terra natal, Alma em flor, Flores da serra, Versos de saudade, Rio de Janeiro, Livraria Garnier.

Sevcenko, Nicolau (1992), Orfeu Extático na Metrópole. São Paulo, sociedade e cultura nos frementes anos 20, São Paulo, Companhia das Letras.

Ligia Kimori é doutoranda em Literatura Brasileira na Faculdade de Filosofia, Letras e Ciências Humanas - USP. Sob orientação da Profạ Telê Ancona Lopez, desenvolve a pesquisa "Mário de Andrade leitor dos parnasianos brasileiros e franceses", com o auxílio da FAPESP que também financiou o mês de estágio complementar da pesquisa no Institut des Textes et Manuscrits (ITEM), em Paris, em novembro de 2016. Principais publicações: "A lição dos mestres: os parnasianos na biblioteca de Mário de Andrade", IEA, no 90, 2017, 215-230; "Lições de versificação: Mário de Andrade, leitor dos parnasianos", Guavira, no 23, 2016, 4654. 